\title{
KONSTRUKTION, REKONSTRUKTION OG STRATEGISKE ESSENTIALISMER
}

\author{
Jørn Borup
}

\begin{abstract}
ENGLISH ABSTRACT: Essentialism has been one of the key critique points against pre-postmodern religious (and cultural) studies, resulting not only in misrepresentations but also in legitimating ethnocentrism and hegemony (as revealed by postcolonial studies). This article claims that constructions ("inventions") and essentialisms are natural and universally to be found in also the other's cultural and religious worlds, and that "strategic essentialism" is an important phenomenon to be studied, but not taken at face value, in scientific nd political debates on representation.
\end{abstract}

DANSK RESUME: Essentialisme og dennes misreprosentation, etnocentrisme og hegemoni (som afsløret af eksempelvis postkoloniale studier) er et af de vigtigste kritikpunkter mod før-postmoderne religions- og kulturstudier. Denne artikel hoevder, at konstruktioner ("opfindelser") og essentialismer er naturlige og universelt udbredte også $i$ de andres kulturelle og religiøse verdener, og at "strategisk essentialisme" er et vigtigt foenomen, der bør studeres, men i videnskabelige og politiske debatter om reprcesentation ikke bør tages på ordet.

KEYWORDS: Essentialism, Invention, Construction, Strategic, Occidentalism, Religion.

"Map is not territory” (Jonathan Z. Smith)

Som oplægget til seminaret ganske rigtigt påpeger, skal man ikke gøre nar af de gamle. Afmærkning af faglige territorier og personlige positioner ved symbolsk forfaderdrab er en strategi, der bør udøves med en vis ydmyg erkendelse af, at viden trods alt hviler på andres viden - og at dekonstruktion forudsætter konstruktion. Selv om en del af de gamle desuden trods alt stadig synes at holde ganske godt vand, er der dog visse af de positioner, de var med til at fremelske, der legitimt har høstet langtidsholdbar kritik. En af disse er anklagen om konstruktion og essentialisering. ${ }^{1}$ En sådan potentiel vildfarelse

\footnotetext{
${ }^{1}$ Typisk for essentialisme er forestillingen om, at et objekt har en uforanderlig og nødvendig, iboende kvalitet, at man kan slutte sig til helheden ud fra delen, og at man kan generalisere attributter fra et element i en given gruppe til også at være konstituerende som attribut for andre elementer i samme gruppe. Mens en sådan operation muligvis inden for visse discipliner vil være uproblematisk, har det inden for humanvidenskaberne
} 
er udfordrende for moderne religionsforskning til besindelse på begrebsliggørelse af egen analyseobjekt og til refleksion over teori og metode. Denne artikel prætenderer ikke at formulere definitioner af (forholdet mellem) religion og kultur eller at give filosofiske eller videnskabsteoretiske forklaringer eller 'løsninger' på sådanne udfordringer. Fokus er her at belyse den videnssociologiske diskurs, hvori essentialistiske forstålser af religion og kultur har været anvendt som strategiske positioner i kultur- og religionshistorien.

\section{Tidlige religionsstudier og konstruktion af de andre}

"Can Asians think?" (Kishore Mahbubani)

Hvorfor overhovedet beskæftige sig med studiet af religion? - kunne man retorisk spørge, og lede teoretiske refleksioner tilbage i historiske linier som betingelser og kontekster for også nutidig religionsforskning. Mens oplysningstid og romantik med rette ofte antages at være den arena, hvor brikkerne for alvor blev samlet til verdensbilledepuslespillet, har de sidste par årtier fokuseret også på kolonialismen som katalysator for senere kultur- og religionsstudier. Udover at have opnået permanent status som faglig disciplin er postkoloniale studier blevet en nødvendig indgangsvinkel til studiet af især asiatiske kulturer og en vigtig øjenåbner for analyse af samspillet mellem magt, repræsentativitet og identitet samt forholdet mellem dem og os, også inden for religionsvidenskaben.

"The study of religions provided knowledge that was useful for a nation that was currently engaged in trading with other countries", citerer David Chidester en britisk teolog for at have sagt i midten af det nittende århundrede (Chidester 2000, 423). Også Max Müller havde en interesse $i$ at lade religionsstudier være en legitim metode til opretholdelsen af det britiske imperium; "classify and conquer" benævnte han sin egen, og angiveligt ganske mange andres, baggrunde for studierne (ibid., 431). Netop klassificering var en kunst, der kunne identificere forskelle mellem dem og os. De europæiske kolonimagter fandt spirituel legitimering ved kristendommen, der til gengæld kunne anvende opdagelsen af de andre til at positionere sig som central magtfokus. Mens dikotomien mellem sandhed og (de andres) religion, mellem tro og overtro, var et selvindlysende faktum, var svaret på udfordringen fra den religiøse mangfoldighed at ordne disse $i$ et hierarki, der kunne stadfæste den kristne verdens universalisme. Hvad enten forskelligheden blev forklaret i Guds skaberværk eller i senere evolutionistiske systemer, var klassifikation i monoteistiske religioner/'verdensreligioner' og 'andre religioner' i lige så høj grad en øvelse i hegemonisk puslespil som en nødvendig metodisk taksonomi (Masuzawa 2005). Hvad antropologien gjorde ved 'de andre' og litteraturstudierne gjorde ved Orienten, gjorde religionsstudierne ved religionerne: "comparative religion operated throughout the world to deny, discover, locate and displace the beliefs and practices of the colonized" (Chidester 2000, 430). (Store) traditioner og ismer blev

været problematiseret at forudsætte essentialistiske og statiske menneske-, samfunds-, kultur- og religionsopfattelser. 
navngivet og konstrueret, tekstualiseret, teologiseret (protestantiseret), homogeniseret og essentialiseret, så religionsforskningen og 'Vesten' kunne spejle og rekonstruere sig ved hjælp af 'de andre'. Postkoloniale - og generelt postmoderne - studier af religion har naturligt nok sat sådanne diskurser under kritik. Er religionsvidenskaben dybest set andet end etno- og eurocentrisk mentalgymnastik, baseret på statisk kultur- og religionsforståelse? Er religionsfænomenologi andet end teologi, hviler religionsvidenskab på naive modernitetsvidenskabsparadigmer, bør 'religion' overhovedet have selvstændig status som studieobjekt? ${ }^{2}$ Har de ikke ret, kritikerne, i at dekonstruktion og revision er nødvendig for rigtig at kunne forstå de andre på et mere humant og videnskabeligt grundlag?

\section{Occidentalisme og konstruktionen af de andre andre}

“Japan as Number One: lessons for America” (Ezra F. Vogel)

Radikale relativiseringsprojekter er altid i fare for at blive fanget $i$ eget spind. Kan man overhovedet tale om en modsætning mellem 'dem' og 'os', mellem et magtudøvende 'Vesten' i forhold til en passiv 'Orient' uden selv at forudsætte essentialismer og konstruktioner? Ud over almen kritik af Edward Saids kendte og indflydelsesrige, men også endimensionelle, orientalismekritik, har et væsentligt punkt været fremdraget, nemlig kritikken af den forudsætning, at konstruktion og magtkamp var og er en ensidig affære. Mens flertallet af de koloniserede og objektiviserede naturligvis har haft begrænsede muligheder for kritisk dialog, endsige muligheden overhovedet for at repræsentere sig selv, har ganske mange eksempler på responser fra især den kulturelle og religiøse elite godtgjort, at også de andres stemmer har været medvirkende til konstruktionen af sig selv og de andres andre; 'Vesten' og 'Occidenten'. Man behøver ikke lide af overdreven etnocentrisme for at konstatere, at også de andres religioner og kulturer har hierarkiske klassifikationssystemer og strategiske interesser $\mathrm{i}$ at marginalisere de andre og definere egne traditioner som unikke og særskilte. ${ }^{3}$ At anvende begreber som "invented traditions" (se nedenfor) samt at antage, at selv nok så selvbevidst traditionalisme nødvendigvis også er udtryk for modernitet, bør derfor heller ikke være ukonventionelt, men kan give diskussionen mellem 'dem' og 'os' et andet og mere komplekst perspektiv.

Det måske klareste eksempel på en sådan vinkel er konteksten omkring hinduistisk og buddhistisk modernitet. ${ }^{4}$ I bestræbelserne på (gryende post-) kolonial selvidentitet, var kulturelle og religiøse repræsentanter fra eliten naturligt opsatte på at frigøre sig fra

\footnotetext{
${ }^{2}$ Postmoderne og post-essentialistisk religionsforskning er i dag en så udbredt tradition, at en tilnærmelsesvis dækkende bibliografi er uden for nærværende artikels ambitioner. En fremtrædende eksponent må siges at være Russell T. McCutcheon, og McCutheon 1997 dækker på mange måder nogle af de ovennævnte positioner og kritikpunkter.

3 “'Western liberal societies' are scarcely the only ones with a 'colonial past' [...] Indeed, western liberal societies may be the only ones in which it has ever been widely believed that there is anything wrong in treating outsiders less well than the already established population” (Barry 2001, 284).

${ }^{4}$ Se Clarke 1997; King 1999; Borup 2005.
} 
kolonimagtens fysiske og mentale åg. Ud over rent politiske tiltag blev kulturelle og religiøse argumenter lagt for dagen af store indiske og srilankanske (og senere japanske) personligheder, hvis stemmer stadig giver genklang i både øst og vest. ${ }^{5}$ Deres form for hinduisme og buddhisme var tydeligvis en reaktion mod, men i ligeså høj grad en omvendt spejling af, de beskrivelser, som religionsforskere og "Indomaniac Orientalists" (Masuzawa 2005, 287) fra Vesten havde identificeret dem med. Den 'romantiske orientalisme' var ganske vist essentialiserende og konstrueret, men gav i modsætning til den 'negative' nær-orientalisme fjern-orientalerne et noget lettere modspil. Det var noget lettere at bygge videre på den skabelon, som var blevet lagt foran dem, og som med et kulturelt fingeraftryk kunne sendes tilbage som en re-konstruktion af en konstruktion. Neo-hinduismen og neo-buddhismen blev ud fra teksttraditioner som Vedanta, dele af pali-kanon og senere også forskellige zenbuddhistiske kilder kendt som spirituel, mystisk, rationel, videnskabelig og kulturelt specifik. Ligesom pizzaen blev transformeret i USA og genopdaget i Italien, undergik de østlige traditioner en form for religiøs og kulturel pizzaeffekt. Efter at være blevet 'opdaget', tekstualiseret, spiritualiseret og populariseret af vestlige forskere og skønånder blev den af Orientens (ofte vestligt uddannede) elitære fortrop - og godt hjulpet på vej af spirituelle fødselshjælpere som teosofferne - genskabt som autentisk udtryk for sand, østlig religiøsitet med virkningskraft også i dag blandt især vestlige buddhister (Borup 2005). En sådan 'omvendt' eller 'spejlvendt' orientalisme, hvor konstruerede billeder vendes på hovedet til egen fordel, kan tilsvares af og er ofte funderet på billeder og re-konstruktioner af Occidenten (Vesten) med samme essentialistiske modbilleder.

Ian Buruma og Avishai Margalit forfølger flere sådanne spor i "Vesten set med fjendeøjne" - undertitlen til deres bog Occidentalism (på dansk: Aftenland, 2004). ${ }^{6}$ Sporene går omkring Mellemøsten, Japan og Rusland og indkapsler flere temaer, der har det tilfælles, at Vesten konstrueres i negative termer i opposition til den position, man selv vil fremhæve. Vesten fremføres som symptom og baggrund for modernitetens sygdom. Den er det store monster, hvor individualisme, egoisme, åndelig forurening, overfladisk materialisme, ugudelighed og underholdning med cola, jazz og lige lovligt løssluppen erotik råder - i modsætning til japansk, muslimsk, russisk etc. ånd, dybde og 'kultur'. Da japanske intellektuelle i 1942 med konferencen "overcoming modernity" (kindai no chōkoku) skulle give deres bidrag til argumenter mod moderniteten, var det ikke blot udtryk for relevant, videnskabelig skepsis over for vestlig kulturimperialisme. Det var samtidig symptom på en navlebeskuende nationalisme, som også i efterkrigstidens Japan (og specielt i bobleøkonomiens dage) periodisk har vist sit ansigt med kulturfunda-

\footnotetext{
${ }^{5}$ Disse tæller vigtige personer som Rammohun Roy, Debendranath Tagore, Swami Vivekananda og Anagarika Dharmapala. De to sidstnævnte tog fusen på arrangørerne af den stort anlagte World Parliament of Religions i Chicago i 1893. Den iscenesatte dagsorden at manifestere kristendommens overlegenhed i datidens nye multireligiøse og internationale arena blev gjort til skamme ved især disses (og i mindre grad japanske Shaku Soens) taler og personligheder, der tog kegler i salen, hos medierne og senere store dele af den orientinteresserede omverden.

${ }^{6}$ En anden anbefalelsesværdig bog om occidentalisme er Carrier 1995.
} 
mentalistiske argumenter for snart sagt hvad som helst. ${ }^{7}$ Islamismen er af nyere dato og har frem for kulturaspektet fokuseret på religion som identitetsmarkør og brand i kampen mod Vesten. Nutidens islamisme som occidentalistisk respons til globalisering og senmodernitet er på mange måder parallel til tidligere occidentalistiske responser til imperialisme og modernitet. Den mytologiserede offerrolle og ritualiserede hellige kamp mod den essentialiserede fjende var den samme for japanske kamikaze-piloter på vej til guddommeliggørelse som for unge martyriumsberusede jihad-krigere i kamp mod ondskaben selv; "de elsker Pepsi, vi elsker døden" (ibid. 51).

De to forfattere argumenterer for, at disse fjendebilleder er skabt af Vesten selv; "de første occidentalister var europæere” (ibid. 26). Mere præcist søger forfatterne grobunden til dette i romantikkens Tyskland, hvor nationalistiske og kulturromantiske ideer om Volkgeist blev brugt som bl.a. modsvar til fransk universalisme, men også marxismens mod-kapitalisme har ifølge dem lagt brænde til bålet og inspiration til fjendebilleder af Vesten, bl.a. hos flere islamister. ${ }^{8}$ Man kunne indvende, at det frem for at identificere én oprindelse til en sådan diskurs og frem for at reducere bevægelsen til udelukkende at være fra et sådant center til periferien vil være mere perspektivrigt at anskue den som udtryk for et mere gensidigt, vekselvirkende kompleks af ideer, personligheder og historiske kontekster. Også europæiske oplysningstænkere og romantikere var stærkt inspireret af, hvad de anså som ‘østlig tankegang'. Hovedpointen er dog den samme; de angiveligt autentiske repræsentationer som alternativer til vestlige konstruktioner er selv konstruktioner.

\section{Opfundne traditioner og "fake religions"}

\section{"Oppression is what we do in the west. What they do in the Middle East is culture"}

Da Eric Hobsbawm og Terence Ranger i 1983 udgav antologien The Invention of Tradition, satte de både gang i faglige diskussioner og formulerede, hvad der for mange er selvindlysende fakta fra humanvidenskabens område: "traditions, (...) that appear or claim to be old are often quite recent in origin and sometimes invented" $(1983,1) .^{10}$ Man kan naturligvis diskutere, hvorvidt det overhovedet er muligt at skelne mellem 'ægte' og 'opfundne' traditioner, og om forandringer og revitaliseringer er væsensforskellige i forhold til et mere dynamisk traditionsbegreb. Perspektivet giver dog en udfordrende mulighed for også at læse aspekter af kultur og religion med andre briller.

\footnotetext{
${ }^{7}$ Nihonjinron (“diskurs om japanerne”) er en helt genre dedikeret til dette, se fx Befu 2001 og Borup 2005.

${ }^{8}$ Mange var uddannet i eller var stærk inspireret af Vesten; Vivekananda, Dharmapala, Ghandhi, Pol Pot, Khomeiney, Said og “occidentalismens ypperstepræst” Sayyid Qutb (Buruma og Margalit 2004, 112) har således alle fået deres inspiration, ideologiske oprustning og/eller deres Vest-alternativer via Vesten selv.

9 Robert Hughes citeret i Barry 2001, 284.

10 Dette formuleres samme steds lidt mere indgående: “"Invented tradition” is taken to mean a set of practices, normally governed by overtly or tacitly accepted rules and of a ritual or symbolic nature, which seek to inculcate certain values and norms of behaviour by repetition, which automatically implies continuity with the past. In fact, where possible, they normally attempt to establish continuity with a suitable historic past" (ibid, 1).
} 
Religionshistorien er på sin vis én lang fortælling om sådanne (også genealogisk beslægtede) forandringsprocesser, hvor myter, ritualer, doktriner og traditioner spejler, udvikler og konstruerer sig i tid og rum. ${ }^{11}$ Der er dog visse cases inden for religionshistoriens raritetskabinet, der lægger op til tydeliggørelse af denne problematik omkring konstruktioner.

Én type konstruktion er, hvad Chidester kalder deciderede "fake religions" (Chidester 2005), bevidst kunstigt skabte traditioner. Hvorvidt internetreligionerne Church of Holy Fucking Shit eller Kick-Ass Post Apocalyptic Doomsday Cult of Love har eksistensberettigelse som andet end ren provokation eller underholdning - og hvorvidt en sådan "inauthentic authenticity" (citeret $\mathrm{i}$ ibid., 227) i så fald nødvendigvis adskiller sig markant fra andre religiøse traditioner - er naturligvis problematisk helt at afgøre. Men det bør høre til religionsforskningens område at undersøge sådanne 'kunstige' religioner, da også disse "can generate genuine enthusiasm and produce real effects in the world" (ibid., 43). ${ }^{12}$ Det samme gælder for bevidst iscenesatte falske lamaer ${ }^{13}$, "fake gurus" og primitivitetsromantiske new age-miljøers frembringelse og markedsføring af 'autentiske shamaner', der i hjemlandet ikke regnes for andet end andenrangs charlataner, ${ }^{14}$ ligesom også jesuitermunkes konstruktion af en 'autentisk hinduisme' i det 18. årh. som bevis for hedenskabens ringe intelligens viste sig at få sin egen, omvendte virkningshistorie, da Voltaire brugte den som udtryk for autentisk kultur hos den oplyste orientaler. ${ }^{15}$ At litteratur i sig selv skaber religion kendes fra hele religionshistorien; men især hippiernes og senere new age-folkets brug og stærkt intentionelle læsninger af især orientalske og naturfolks traditioner har i forskellige litterære produktioner fået ikke bare kultstatus, men decideret skabt religiøsitet - og skæve repræsentationer af orientalerne og naturfolkene. Når Castanada og Vagn Lundbye idealiserer og konstruerer 'de vilde', når 'zen og kunsten at ...-bøger' i sig selv får vesterlændinge til at medi-

\footnotetext{
${ }^{11}$ Ud over mere generelle forandringer kunne konkrete eksempler nævnes; når balinesere kreerer hellige tempeldanse for at afpasse turisters ønsker, når pilgrimsruter tilpasses nye omstændigheder (som turisters eller busselskabers tidsplaner) eller når nye begravelsesritualer afstemmes moderne teknologi.

${ }^{12}$ Mens sådanne mulige "fake religions" trods alt bør overholde visse spilleregler ved ansøgning om eksempelvis status som godkendt trossamfund, er det lidt sværere for fagkonsulenter på internetportaler at kategorisere sådanne. Da "Discordians" efter at have været placeret i kategorien "parody religions" med mailkampagner opfordrede til enten at blive rekategoriseret som "real religions" eller at lade sådanne kategorisere som parodier, havde de en underholdende - men dog fagligt ganske interessant - pointe (Chidester 2005, 199).

${ }^{13}$ At forfatteren bag den angiveligt tibetanske mester Lopsang Rampa var en britisk blikkenslagersøn, der aldrig havde sat sit ben i sit mystificerede Tibet, var knap så interessant som det faktum, at hans bøger stadig 50 år efter sælger som gedigne udtryk for østlig mystik - og at identifikation af sande og afsløring af falske lamaer i sig selv er blevet en industri især indenfor moderne vestlig buddhisme. Især Tibet har fåt flere Hollywood-romantiseringer på bagen, og netop medieskabt kultur og religion er da også en efterhånden blomstrende industri.

${ }^{14}$ Eksemplerne er fra Chidester 2005, 218 og 171-189.

${ }^{15}$ En parallel underfundig historie finder vi i et middelalderskrift, der angiveligt var kristent, og som gode kristne brugte som opbyggelig historie til deres børns opdragelse. Det var først senere, man blev opmærksom på, at disse var omskrevne udgaver af Buddhalegenden.
} 
tere, når psykologer og terapeuter konstruerer tantra, zen og yoga for at bruge disse $\mathrm{i}$ egne selvudviklingsfilosofier og -metoder, når idealer om 'oprindelige' matriarkalske samfund indgår i moderne spirituelle ideologier, når australsk aboriginalkultur markedsføres med en new age-idealiseret 'dreamtime', er alle disse udtryk for idealiserende projektioner på sin vis positive, men dog ofte essentialiserende. ${ }^{16}$ Det samme er tilfældet, når de andre ubevidst tager stereotyperne til sig og bliver integreret som identitetsskabende og performativ storytelling i disses kulturelle og religiøse universer, som når asiatiske buddhister tager til Vesten for at lære sand buddhisme, når personer fra det indre New Guinea begynder at tygge betel, fordi man fra stereotyper har lært at identificere sig med dette i forhold til europæernes øldrikkeri, når identitetssøgende andengenerationsmuslimer begynder at gå med slør eller insistere på sharia, fordi de får at vide, det er oprindelig og sand religiøsitet, eller når danskere bliver rigtig danske og kristne og etnicitetsromantikere i mødet med de andre. Eller når sådanne konstruktioner vendes tilbage på afsenderne i transformeret udgave - som pizzaeffekten, islamisme, occidentalisme og andre bevidst opfundne traditioner er slående eksempler på.

\section{Strategiske essentialismer og hermeneutiske cirkelslutninger}

"I am one, so I know" (Davis 1992, 6)

Når opfundne traditioner og konstruerede sandheder indoptages og bruges af udøvere som udtryk for autentisk tradition, illustrerer det ganske fint det dynamiske og evigt foranderlige aspekt ved kultur og religion, der netop ikke er statisk, ren og 'oprindelig'. Også opfundne traditioner 'virker', uanset om de måtte være baseret på misforståelser eller er bevidste konstruktioner, og som tidligere påpeget er det svært overhovedet at opretholde ideen om 'rene' traditioner. Religionsvidenskaben bør i en vis forstand - i modsætning til ideer om essentialistiske oprindelser - betragte alle opfundne traditioner som naturlige og som interessante cases for analyse. Når opfundne traditioner politiseres og udfordrer 'Vesten' eller 'videnskaben' i magtkampe, hvad enten disse er postkoloniale udfordringer til etnocentrisme eller 'indfødte'/hjemlige traditioners autenticitetsretorik, afkræves religionsforskningen dog også analytiske strategier i responsen til sådanne udfordringer. Med udgangspunkt i responsen til postkolonial kritik identificerer David Chidester to mulige (yder)positioner. Den ene kalder han indigeneity eller indigenism ('indfødthed' eller 'nativisme'). Denne er kulturrelativistisk og insisterer på kulturel differentiering, "the recovery of place, the authenticity of tradition and the assertion of self-determination in ... indigenous terms" (Chidester 2000, 433). Denne strategi lægger op til de- og rekonstruktion af forskningstraditionens forhold til 'de andre' og kan forfølges både 'udefra' som en analytisk position og 'indefra'. 'Going native" kendes både fra antropologien og religionsforskningen som argument for over-

\footnotetext{
${ }^{16}$ Et eksempel på negative konsekvenser af ellers "positive essentialiseringer" er, når asiatiske "modelimmigranter" skal leve op til deres angiveligt ideelle habitus (Kibria 2002, 132-33). Nogle gange giver det en vis etnisk identitets-kapital at spille "authenticity play" (ibid., 94-95), men det kan også være et åg at bære rundt på en "falsk varebetegnelse", når man ikke kan efterleve idealerne og stereotyperne.
} 
skridelse af emic/etic-distinktioner, og der er rigeligt med eksempler på repræsentanter fra disse fag, der er blevet shamaner, paganister, mystikere, buddhister, satanister, muslimer eller kristne. At undervise i religion også på universitetsplan i overensstemmelse med repræsentationer fra religionernes egne normative idealer kan være ét udtryk for denne position, hvorfor visse forskere lægger op til normativ tilgang, og ofte med den underforståede pointe, at man skal være religiøs for at kunne forstå religion. Ud over den almene religionsvidenskabelige skepsis mod apologetisk religionsstudier vil en sådan position være problematisk af flere årsager. Den vil i studiet af (især ikkevestlige) religioner ofte forudsætte muligheden for gennem insiderens angiveligt mere objektive anvisninger at nå frem til en før-moderne, før-vestlig 'ren' religion, og den vil - hvis den skal nå ud over ekstrem partikularisme - have problemer med at manøvrere rundt i de forskellige stemmers krav på repræsentativitet. Det synes dog heller ikke indlysende at afløse gammeldags etnocentrisme med ny, projiceret autenticitetsretorik og ontologisk essentialisme under parolen jeg er, derfor ved jeg!

Postkoloniale og anti-orientalistiske studier har ofte været direkte politiserende eller ubevidst lagt arena til politiske dagsordener, ofte med henvisninger til at nå bag om 'vestlige konstruktioner' med formålet at iklæde nye konstruktioner og idealiseringer objektivitet. I den forstand kan man sige, at de eksemplificerer, hvad Gayatri Spivak kalder 'strategisk essentialisme' (1990): (periodisk) iklædning af fælles identitet hos grupper, hvis fælles interesser i opnåelse af politiske mål ideologisk neutraliserer de egentlige forskelligheder. I mødet med 'Vesten' og 'moderniteten' var sådanne strategier naturlige og på sin vis forståelige og moralsk-politisk acceptable; men de var netop ikke neutrale eller 'autentiske'. Det samme er gældende i nutiden, hvor religion og kultur som selvreferentielle forklarings- og legitimeringsfaktorer har fået fornyet vind $\mathrm{i}$ sejlene. 'Religion' er blevet gen-sakraliseret og ophøjet til også at være en politisk hellig ko, og 'kultur' har i visse fora samme status, som 'race' tidligere havde ${ }^{17}$ Når kulturer essentialiseres som aktører i fx civilisationssammenstød, vil dette som forklaringsgrundlag i sig selv kunne fungere som skyts til selvopfyldende profetier, på samme måde som mytologisering og sakralisering af politiske interesser ('det er jo vores kultur/religion...') i kulturrelativismens og religionstolerancens navn har fået anderledes legitimerende stemmer i den offentlige diskurs. ${ }^{18}$ Samme essentialisering kommer på tale, når religion forsøges afpolitiseret og ophøjet som berøringsfri zone, som 'ren religion', i medier og af meningsdannere ofte reduceret til sådannes tekstualiserede kanoner - for her må vi vel kunne se, i deres rene og uforfalskede originaler, religion som den er

\footnotetext{
17 “We are about to make 'culture' into a new concept of race” (Wikan 2002, 81).

${ }^{18}$ Alt fra æresdrab og tvangssterilisation til kreationisme i skolen, asiatiske lederes selviscenesættelse ved påberåbelse af "asiatiske værdier" eller arabiske og mellemøstlige mullahers lejlighedsvise klagesang om krænkelser af deres religion ved mindste løft med vestlige øjenbryn har i den offentlige debat været accepteret som udtryk for 'deres kultur/religion'. "The correct defence of the British government's not punishing Rushdie or handing him over to others for punishment [...] is not "This is the way we do things here". It is, rather, that this is the way things ought to be done everywhere: we do things that way here not because it is a part of our culture but because it is the right thing to do" (Barry 2001, 284).
} 
Konstruktion, rekonstruktion og strategiske essentialismer

i sig selv ${ }^{19}$

Chidesters andet alternativ kalder han hybriditet eller hybridisering (ibid.). Denne forudsætter 'kreolske' kulturer og religioner som foranderlige, hybride og komplekse, kognitivt inkoherente, ad hoc synkretistiske og præget af diversitet, og den fokuserer på den dynamiske relation, der også er mellem den analyserende og det analyserede. Kultur forstås da ikke som en essentiel bagage, der vandrer 'fra generation til generation', men som symboler og praksisformer, der nok kan have fælles referencepunkter, men som konstant er i forandring og til forhandling. Uden at forkaste religionsbegrebet og antagelsen af, at essentialismer også "do exist as pragmatically successful conventions" (Saler 2000, 202), kan religion også i den sammenhæng forstås som "an open and fluid set of discursive, practical and social strategies for negotiating person and place in an intercultural world” (ibid. 435). Ved også at fokusere på 'de andres' strategiske essentialismer som rekonstruerede virkeligheder og idealer i en politisk retorik, flere af disse endog inspireret, legitimeret og konstrueret af 'Vesten', nås megen forståelse af 'kultur' og 'religion'. Kulturforskelle og udfordringer til videnskabelige og politiske virkeligheder er naturligvis altid del af den nødvendige, selvrefleksive proces, der godtgør, at religionsvidenskaben ser sig som netop del af en videnskabelig tradition med en vis robusthed. At udfordre religionsvidenskabelige teorier og begreber eller at postulere Kong Fuzis etik som kinesisk modsvar til Max Webers protestantiske etik er både legitimt og interessant. Men religions- og kulturforskeren bør også være opmærksom på ikke at lade sig forføre af strategiske essentialismer. Disse er helt naturlige, og skal tages alvorligt. Men de skal ikke nødvendigvis tages på ordet.

\author{
Litteratur \\ BARRY, BRIAN \\ 2001 Culture and Equality: an Egalitarian Critique of Multiculturalism, Harvard University \\ Press, Cambridge, MA. \\ BEFU, HARUMI \\ 2001 Hegemony of Homogeneity: an Anthropological Analysis of Nihonjinron, Trans Pacific \\ Press, Melbourne. \\ BORUP, JøRN \\ 2005 Zen and the Art of Inverting Orientalism: Buddhism, Religious Studies and Interrelated \\ Networks" i Peter Antes, Armin W. Geertz og Randi R. Arne (eds.) New Approaches to \\ the Study of Religion. Volume 1: Regional, Critical, and Historical Approaches, de \\ Gruyter, Berlin/New York. \\ BURUMA, IAN \& AVISHAi MARGALIT \\ 2004 Aftenland: Vesten set med fjendeøjne, Lindhart og Ringhof, København. \\ CARRIER, JAMES G., ED. \\ 1995 Occidentalism. Images of the West, Clarendon Press, Oxford
}

\footnotetext{
${ }^{19}$ I disse tiders kulturkamp og Muhammedkriser har netop Bibelen og Koranen fra begge sider - blandt religiøse personer, medier, politikere og amatørkryptologer - været hevet frem som argument for både det ene og det andet.
} 
CHIDESTER, DAVID

2005 Authentic Fakes: Religion and American Popular Culture, University of California Press, Califonien.

Clarke, J. J.

1997 Oriental Enlightenment: the Encounter Between Asian and Western Thought, Routledge, London.

DAVIS, Winston

1992 Japanese Religion and Society. Paradigms of Structure and Change, SUNY University of New York Press, New York.

HOBSBAWM, ERIC, AND TERENCE RANGER

1983 The Invention of Tradition, Cambridge University Press, Cambridge.

KIBRIA, NAZLI

2002 Becoming Asian American: Second-generation Chinese and Korean American Identities, Johns Hopkins University Press, Baltimore.

KING, RICHARD

1999 Orientalism and Religion: Postcolonial Theory, India and "the Mystic East", Routledge, London.

MAHBUBANI, KiSHORE

2004 Can Asians Think?, Marshall Cavendish International, Singapore.

MASUZAWA, TOMOKO

2005 The Invention of World Religions or, How European Universalism was Preserved in the Language of Pluralism, University of Chicago Press, Chicago.

McCutcheon, Russell T.

1997 Manufacturing Religion: the Discourse of Sui Generis Religion and the Politics of Nostalgia, Oxford University Press, New York.

SALER, BENSON

2000 Conceptualizing Religion: Immanent Anthropologists, Transcendent Natives, and Unbounded Categories, Berghahn, New York/Oxford.

SMITH, JONATHAN Z

1978 Map is not Territory: Studies in the History of Religions, E. J. Brill, Leiden.

SPIVAK, G.C.

1990 The Post-Colonial Critic: Interviews, Strategies, Dialogues, Routledge, New York.

VOGEL, EZRA F

1979 Japan as Number One: Lessons for America, Harvard University Press, Cambridge.

WIKAN, UNNI

2002 Generous Betrayal: Politics of Culture in the New Europe, University of Chicago Press, Chicago.

Jørn Borup

Adjunkt, ph.d.

Afdeling for Religionsvidenskab

Aarhus Universitet 